\title{
Hockey stick incision: a modified technique for chest wall masculinization
}

\author{
Alexandra Junn ${ }^{1 \#}$, Sumun Khetpal ${ }^{1 \#}$, John Smetona ${ }^{1}$, Jacob Dinis ${ }^{1}$, Allister Hirschman ${ }^{1}$, \\ Mohammad Ali Mozaffari ${ }^{1}$, Anusha Singh ${ }^{1,2}$, Ann Hui Ching ${ }^{1,3}$, Michael Alperovich ${ }^{1}$, Xiaona Lu ${ }^{1}$, \\ John A. Persing ${ }^{1}$
}

${ }^{1}$ Division of Plastic and Reconstructive Surgery, Yale University School of Medicine, New Haven, CT, USA; ${ }^{2}$ Department of Plastic and Reconstructive Surgery, MedStar Georgetown University Hospital, Washington, DC, USA; ${ }^{3}$ Yong Loo Lin School of Medicine, National University of Singapore, Singapore

Contributions: (I) Conception and design: S Khetpal, A Junn, A Hirschman, J Smetona, X Lu, M Alperovich, JA Persing; (II) Administrative support: X Lu, M Alperovich, JA Persing; (III) Provision of study materials or patients: M Alperovich, JA Persing; (IV) Collection and assembly of data: S Khetpal, A Junn, MA Mozaffari; (V) Data analysis and interpretation: S Khetpal, A Junn, J Dinis, MA Mozaffari, J Smetona, X Lu; (VI) Manuscript writing: All authors; (VII) Final approval of manuscript: All authors.

\#These authors contributed equally to this work.

Correspondence to: John A. Persing, MD. Division of Plastic Surgery, Yale School of Medicine, Department of Surgery, 330 Cedar Street, Boardman Building, 3rd Floor, New Haven, CT 06510, USA. Email: john.persing@yale.edu.

Background: Chest wall masculinization is often performed for transgender men in order to address gender dysphoria. Peri-areolar and double-incision mastectomy with free nipple grafts, are the most common techniques employed in chest masculinization surgery, but are limited by their relative inconsistency and inefficiency in reconstructing a natural anterior contour that comprehensively resembles that of a cismasculine chest. The purpose of this study is two-fold. The first is to describe the "hockey stick" approach, which expands on the widely performed double-incision mastectomy to the axilla, with an additional step of revising lateral chest wall folds of tissue excess. This technique is scalable to the degree of pre-operative excess tissue on the anterior and lateral chest wall. The second is to compare the "hockey stick" incision to existing reconstructive options, with respect to clinical outcomes and patient satisfaction.

Methods: Patients who received chest masculinization surgery at Yale-New Haven Hospital were included. A retrospective chart review, comprising demographic variables, procedural details, and post-operative events, was conducted. Selected modules from a validated survey instrument, the BODY-Q, were measured. Patients were classified by body mass index and incision, which included peri-areolar, inframammary fold, and "hockey stick" incision by date.

Results: Twenty-seven of 73 (37.0\%) participants completed the full survey and were included in the analysis. The "hockey stick" incision had comparable patient satisfaction and post-operative outcomes, compared to peri-areolar and double-incision mastectomy with free nipple graft techniques. Greater BMI patients had a higher incidence of wound dehiscence, compared to other weight classifications.

Conclusions: The "hockey stick" incision is a readily performed, effective surgical technique for building a cis-masculine appearing chest in transgender men with efficient and predictable outcomes. While performed in patients with higher BMI, the "hockey stick" confers equivalent patient satisfaction and clinical outcomes to peri-areolar and double-incision mastectomy.

Keywords: Chest masculinization; transgender; BODY-Q; hockey stick incision; body mass index (BMI)

Submitted Nov 26, 2020. Accepted for publication Jan 08, 2021.

doi: $10.21037 /$ atm-20-7678

View this article at: http://dx.doi.org/10.21037/atm-20-7678 


\section{Introduction}

Gender-affirming surgical procedures modify an individual's body to achieve congruence with one's gender identity or expression (1-7). Chest masculinization surgery, or "top surgery," represents one of the most common genderaffirming procedures performed for transmasculine (those assigned female at birth who identify as male/masculine) and non-binary (those who may experience a gender identity that is neither exclusively male or female) patients (8). The ultimate goal of chest masculinization surgery is to alleviate gender dysphoria and achieve gender congruence. In doing so, an improved sense of self-confidence, safety, psychological well-being, and sexual satisfaction (9-14) may be conferred. These considerations are addressed through several mechanisms: (I) removal of breast tissue and excess skin, (II) appropriate reduction in size and placement of the nipple-areolar complex to a more typical masculine position, (III) elimination or diminishment of the inframammary fold, (IV) minimization of anterolateral chest skin/fat folds, and (V) low complication/revision rates and efficiency of the procedure (15-19). While the appropriate reconstruction details vary among individual patients, chest masculinization surgery is performed in order to achieve an aesthetic result that resembles a cis-masculine chest. It is important to note, however, that the concept of binary gender and any assumed transmasculine aspiration of cisnormalcy is problematic for some. Thus, these specific considerations should be explored in future investigations, as well as within the context of each pre-operative patientsurgeon discussion of surgical options and expectations, risks and benefits, and informed consent (20).

Several techniques, including those utilized for gynecomastia, aesthetic mastopexy, and breast reduction, have been widely adapted for chest masculinization surgery. These approaches include the semicircular peri-areolar, otherwise known as the "keyhole mastectomy," mastectomy with peri-areolar skin excision, trans-areolar, concentric circular extended concentric circular, and inferior pedicle tunnelized nipple-areolar complex (NAC) (21-26). Choice of technique principally depends on patient-specific characteristics, which include overall body habitus, position of the NAC, breast volume, skin envelope, grade of ptosis, and skin elasticity $(15,24,27)$.

Two of the most common techniques for chest masculinization surgery include the peri-areolar mastectomy and the double-incision mastectomy with free nipple grafts (DMFNG) (24-31). The peri-areolar mastectomy is most appropriate for patients who have minimal excess breast volume, and skin, and good skin elasticity (i.e., few or no stretch marks in the breast region) (24-26). Advantages of this procedure include a small, well-concealed scar may. However, this technique carries the risk for surgical site complications (i.e., hematoma, scar revision, seroma) and breast ptosis requiring repeat intervention (24-26). Alternatively, the DMFNG is the most common surgical option in patients with larger pre-operative breast mass (24-26). This particular technique provides excellent exposure, optimization of the NAC position, low revision rates, and high patient satisfaction. However, it is associated with heavier scar burden, and often includes lateral chest wall scars and visibility or retained folds of skin, breast tissue and fat, which may require further time occupying revision procedures (24-31) (Table 1).

Despite the widespread utilization of the DMFNG for chest masculinization, there have been notable refinements to the procedure in achieving a chest contour that resembles that of a cis-male $(24,32,33)$. This entails congruity of the inferolateral margin of the pectoralis major through the extension of either the upper or lower incision into the axilla $(24,32,33)$. In addition, the lengthening of the lateral inframammary fold (IMF) incision into areas of greater scar visibility has been described to address puckering or tethering at the lateral chest wall soft tissue $(24,32,33)$.

This article shares an adapted approach, the "hockey stick," which builds on previous techniques to achieve a cis-masculine appearing chest contour. Accompanying videos demonstrate key steps in the procedure, including preoperative marking of the incision lines (Video 1) and intraoperative technique steps (Video 2). We also sought to evaluate how the "hockey stick" technique compares to conventional DMFNG and peri-areolar approaches in terms of patient satisfaction and clinical outcomes. These were assessed through the BODY-Q, survey instrument, and a retrospective chart review (34). Thus, the purpose of this study is two-fold: (I) to clarify the proposed technique relative to refinements defined by body habitus; (II) to compare the "hockey stick" incision to existing reconstructive options with respect to clinical outcomes and patient satisfaction, namely to explore the impact of surgery on gender dysphoria and the achievement of gender congruence in chest masculinization surgery. We present the following article in accordance with the STROBE reporting checklist (available at http://dx.doi.org/10.21037/ atm-20-7678). 
Table 1 Comparative advantages and disadvantages of various incision types for chest masculinization surgery

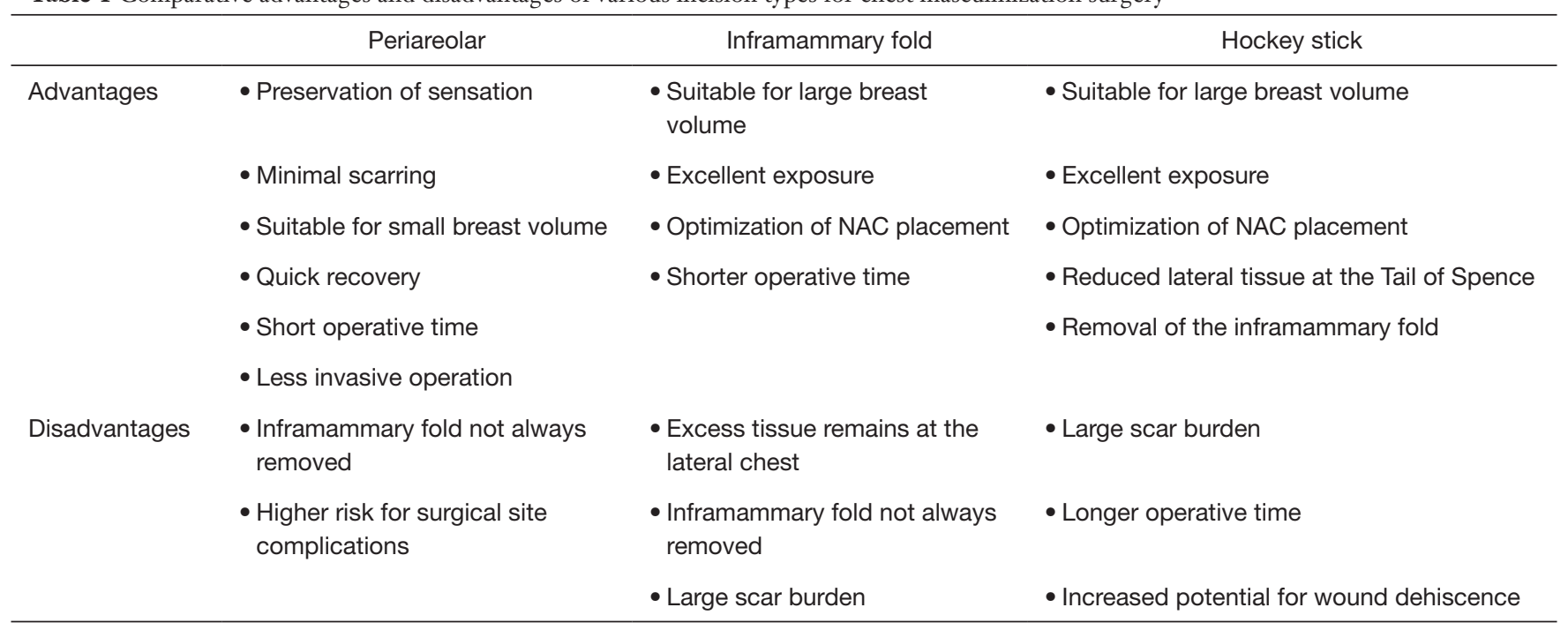

\section{Methods}

Clinical and patient-reported outcomes were assessed through a retrospective chart review and BODY-Q (Memorial Sloan Kettering, New York, NY, USA), a validated survey instrument that had been previously developed in order to assess patient satisfaction from body contouring or weight loss surgery (34-38). The survey tool has been formally validated for transgender men undergoing chest masculinization surgery (38). The study was conducted in accordance with the Declaration of Helsinki (as revised in 2013). The study was approved by institutional review board of Yale School of Medicine (NO.: 2000022992) and informed consent was taken from all individual participants.

\section{Retrospective chart review}

Following approval from the Yale University Institutional Review Board (HIC\#2000022992), a retrospective chart review of transgender male patients who underwent chest masculinization by two Yale Medicine Plastic and Reconstructive surgeons (MA and JP) between May 2016 and August 2020 was conducted. These patients were classified into four cohorts, guided by incision type and time of surgery: (I) peri-areolar, (II) inframammary fold incision, (III) "hockey stick" incision (performed before July 2019), and (IV) "hockey stick" incision (performed after July 2019). The technique of the hockey stick incision was developed over the course of several years through the experience of the senior author. July 2019 was selected as the cutoff point between cohorts 3 and 4 , as it was the time at which the procedure had become consistent without need for additional refinement. Demographic variables such as age, body mass index (BMI), race, insurance status, ASA class, comorbidities, and smoking status were collected. In order to assess potential influence in post-operative events as well as to examine any notable trends among our patient population, complications, re-admissions, and reoperations, were also assessed. Furthermore, patients were stratified by $\mathrm{BMI}$, as normal weight $(\mathrm{BMI}<25)$, overweight (BMI between 25-30), and obese (BMI >30) groups (35). Procedural details were summarized, including volume of liposuction, breast tissue removed, and perioperative complications. Complications considered include deep venous thrombosis (DVT), hematoma, seroma, infection, fat necrosis, nipple necrosis, readmission within 30 days, readmission within 90 days, relevant Emergency Department (ED) visits post-surgery, and re-operation.

\section{Survey design and development}

Selected modules from the BODY-Q were used to assess appearance, quality of care, and experience of care (34-38). Only postoperative patients' data were included. Survey responses were classified by the aforementioned cohorts. The included modules are detailed (Table 2). 
Table 2 Description of various body-Q modules distributed to patients

\begin{tabular}{lcll}
\hline Category & Items & \multicolumn{1}{c}{ Example item } & 4-point Likert response options \\
\hline Appearance-related distress & 8 & "I feel anxious when people look at me" & Definitely disagree-definitely agree \\
Chest & 10 & Appearance in a snug t-shirt & Very dissatisfied-very satisfied \\
Nipples & 5 & Nipple size & Very dissatisfied-very satisfied \\
Psychological & 10 & "I am emotionally strong" & Definitely disagree-definitely agree \\
Social function & 10 & "I feel confident when I am in group & Definitely disagree-definitely agree \\
& 7 & situations" & All the time-never \\
Physical function & 10 & Difficulty getting up from a bed & Definitely disagree-definitely agree \\
Satisfaction with doctor/surgeon & 10 & Were attentive to your needs & Definitely disagree-definitely agree \\
Satisfaction with office staff & 10 & Answered all your questions & Definitely disagree-definitely agree \\
Satisfaction with medical team & 10 & Length of scars & Extremely bothered-not at all bothered \\
Appraisal of body contouring scars & &
\end{tabular}

\section{Survey distribution}

The survey was distributed via email through the Health Insurance Portability and Accountability Act (HIPAA) of 1996-compliant Qualtrics Software (Qualtrics, LLC, Provo, Utah). Patients were called in advance before the survey was sent to them in order to share the goals of the research investigation in order to maximize participation in the study and limit response bias. Responses were collected over a one-month timeframe at the time of chart review. Participation was voluntary and respondents did not receive any form of compensation for survey completion.

\section{Statistical analysis}

Statistical analysis was conducted utilizing chi-square tests to compare categorical data between groups (SPSS, v.25.0, IBM Corp., Armonk, NY). Patients were included in the analysis only if they had complete data. Data were considered non-parametric if they were ordinal, or if they fit a non-normal distribution as determined by the Shapiro-Wilk test. Continuous data was analyzed via oneway ANOVA for parametric data, and Kruskal-Wallis with Monte Carlo estimate for non-parametric data. Welch's ANOVA was used for data in which there was unequal homogeneity of variances between groups, as determined by Levene's test. Post-hoc analysis of significant findings with ANOVA was completed with Bonferroni, and for Welch's ANOVA with Dunnett's T3 test. Statistical significance was set at $\mathrm{P} \leq 0.05$.

\section{Operative technique}

Hockey stick incision extending into the axilla

A step-by-step illustration of the technique can be seen in Figure 1. The "hockey stick" incision consists of two horizontal incisions, one at the IMF (horizontalized medially), and the other at the overlapping of the superior horizontal incision line above the upper limit of the NAC (Video 1). The superior breast incision is curvilinear and longer than the IMF incision, accounting for the additional skin overlying the breast tissue mound. The lateral limits are along the lateral border of the pectoralis muscle border the IMF and the anterior axillary line. The incision line is marked as an oblique line, just posterior, $(1 \mathrm{~cm})$ to the lateral border of the pectoralis muscle, and an anteroposterior transverse plane approximately 2 centimeters $(\mathrm{cm})$, inferior to the axillary crease. The transverse incision line length in the axillary skin in a moderate-sized breast and body habitus, is approximately $7 \mathrm{~cm}$ antero-posteriorly. Importantly, this dimension is also defined on the posterior vertical-oblique oriented limb incision in the lateral chest wall. This line is defined by the most posterior point of the transverse incision in the axilla to its intersection with the IMF and the inferior extent of the anterior axillary line which runs along posterior border of the pectoralis muscle until the IMF (Note: The adjustable $7 \mathrm{~cm}$ incision line is based on patient body habitus. In patients with greater $\mathrm{BMI}$, the incision may be extended to $8-9 \mathrm{~cm}$, while those with lesser BMI without folding of lateral chest wall tissue may not even require resection at the transverse axillary 
A

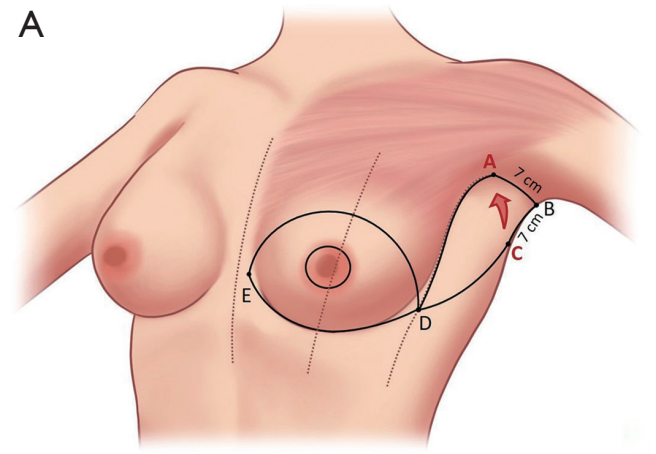

C

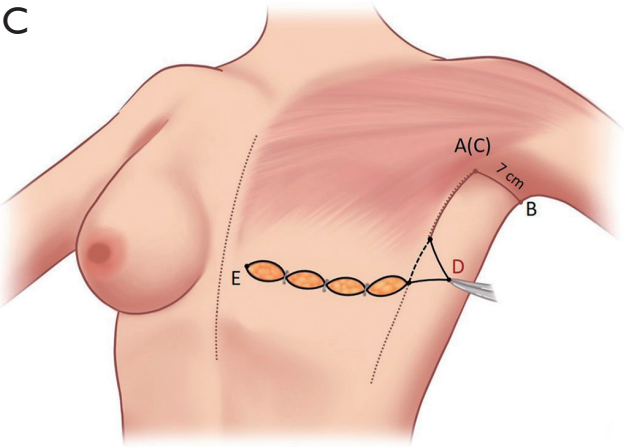

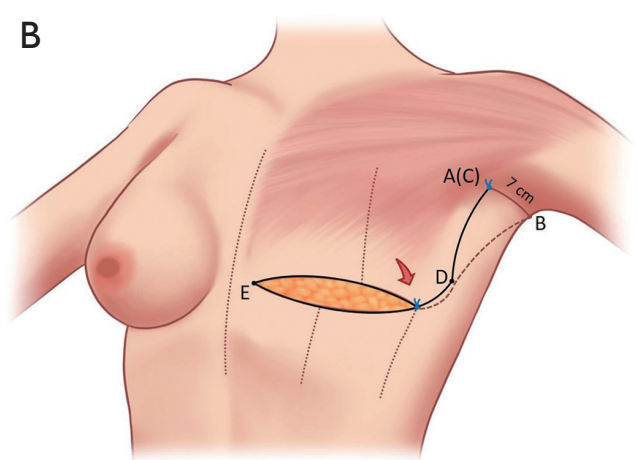

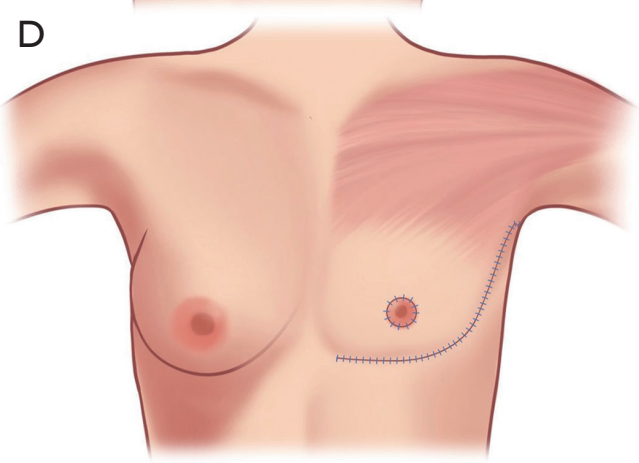

Figure 1 Simple illustration depicting key steps of the hockey stick procedure. A is at a point $5 \mathrm{~mm}-1 \mathrm{~cm}$ behind the pectoralis where the pectoralis meets the anterior axillary line. B represents the pivot point $7 \mathrm{~cm}$ posterolateral from A. B is joined to meet D which is located on the anterior axillary line. E represents the most medial point of the double incision, and both the superior and inferior incisions are brought to meet the anterior axillary line at D. (A) C is a point on the line BD that is $7 \mathrm{~cm}$ inferior from B. C is rotated upward to meet A. (B) The midclavicular line on the superior flap is brought laterally to avoid dog ears medially. (C) Excess tissue at point D is removed, which equalizes the length of the superior and inferior flaps, as well as ensures a scar that slopes upwards along the outline of the pectoralis muscle. (D) Final closure of the incision shows the segment $\mathrm{A}(\mathrm{C})-\mathrm{B}$ is hidden in the axillary fold.

level. This dimension will be consistently referred to as "7 cm" hereafter for clarity). This technique also allows for reduction of any excess tissue along the lateral chest wall to include the tail of Spence (Figures 2-4).

The inferior incision in this technique is continued slightly more medially compared to the traditional inframammary fold incision and is flattened horizontally to further add greater symmetry in this now more visible aspect of the chest wall. But importantly, it is not joined directly to the contralateral breast IMF. The superior breast incision is carried out largely in a horizontal plane at the level of the overlap of the areola with the inframammary fold centrally, while the breast is pulled inferiorly under tension. The margins of the incision line taper off medially and laterally, as described earlier. As a result of the convex breast contour superiorly, the length of the superior incision line ultimately exceeds that of the inferior IMF incision line. To address this length discrepancy, the midline of the clavicle (which is marked at the beginning of surgery on the superior flap as a reference line) is advanced laterally during closure, such that the midline of the superior line joins the inferior midline (about $2-2.5 \mathrm{~cm}$ further laterally) to account for the excess length imposed as a result of the convexity of the breast mound incision line (Figure 5). The lateral chest wall skin excess will be discarded later as overlap tissue along the line of the lateral pectoralis muscle border.

In re-approximating the axillary incision line, a point $7 \mathrm{~cm}$ inferior from the posterior- most corner of the horizontal axillary incision line is rotated to the junction of the anterior most point of the horizontal incision line at the anterior axillary line (Figure 6). This flattens the redundancy of the lateral chest excess tissue seen in most patients to some degree with a BMI greater than 20. Moreover, this technique places the scar line only at the posterior border of the pectoralis muscle, from the IMF to the axilla. 

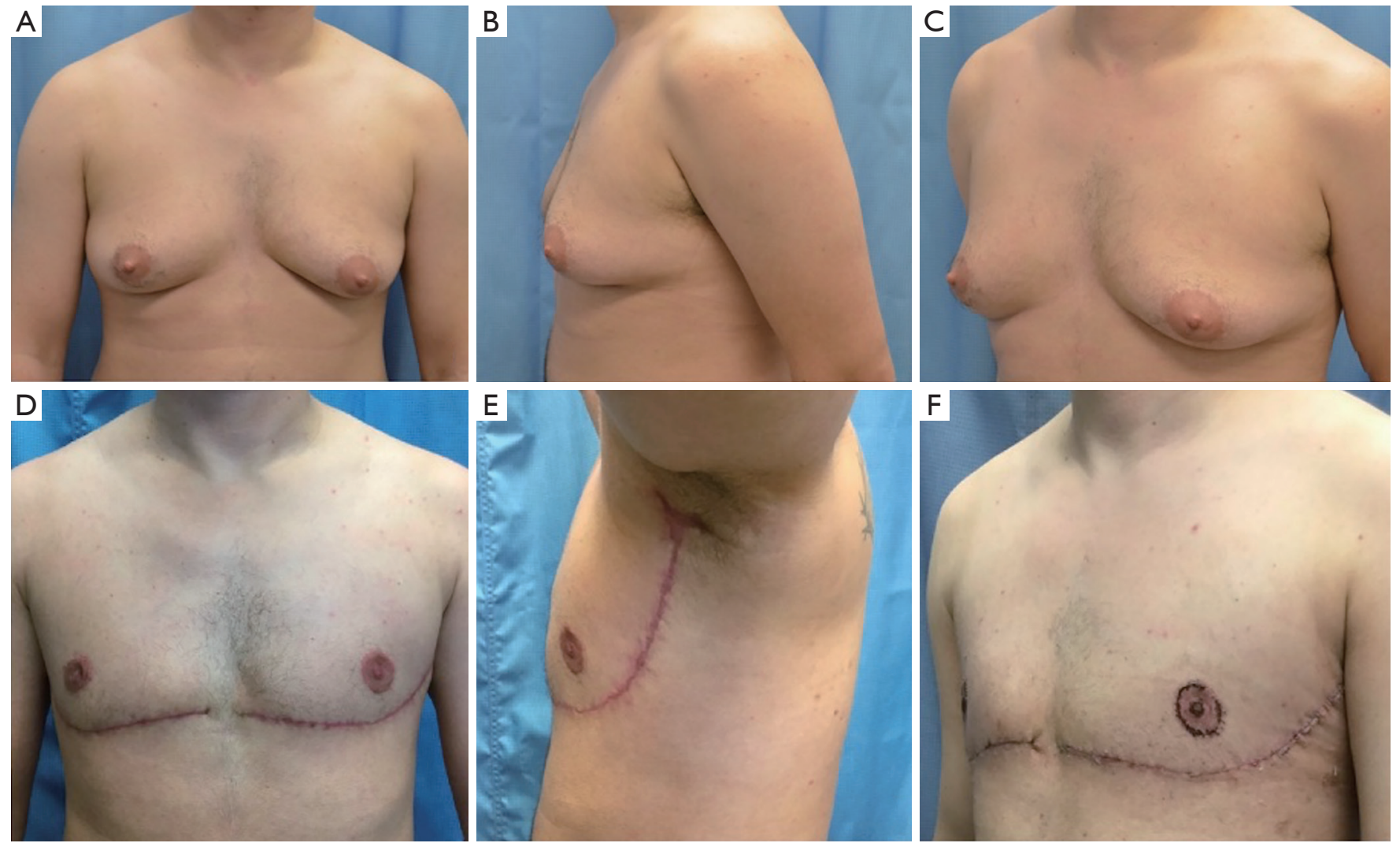

Figure 2 Pre- and post-operative photos of a patient who underwent the hockey stick procedure. Pre- and post-op photographs of a patient with BMI 26.55. (A,B,C) Figures demonstrate pre-op photos from the front, lateral, and 45 degrees lateral view, respectively. (D) Figure shows the final result at 2 months from the anterior view. (E) Figure shows demonstrates axillary extension which is hidden in the axillary crease. (F) Figure shows a 2 -week post-op photo from the 45 degrees lateral view, where the outline of the pectoralis muscle by the incision line can be appreciated.
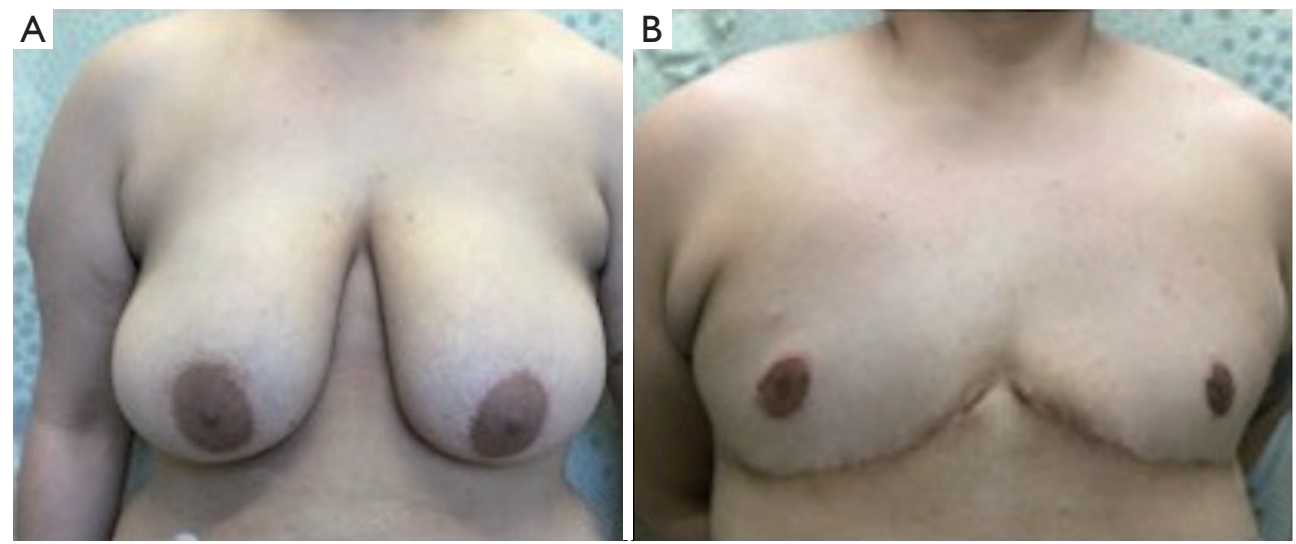

Figure 3 Patient with BMI 32.61 who underwent the hockey stick procedure. (A,B) Figure represent pre-op and post-op at 8 months respectively. 

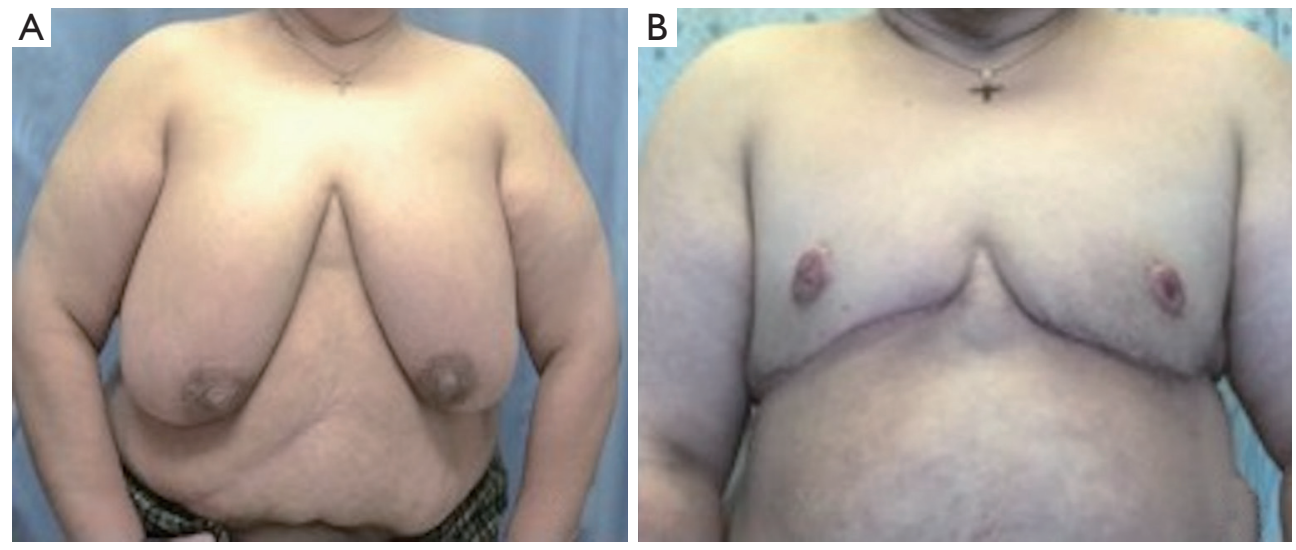

Figure 4 Patient with BMI 40.3 who underwent the hockey stick procedure. (A,B) Figure represent pre-op and post-op at 7 months respectively.

\section{Adjustments by BMI}

The "hockey stick" incision allows for fine tuning adjustments, both vertically and horizontally, based on BMI (performed in the pre-operative assessment of skin and fat excess.) In patients with lower BMI and limited breast ptosis, the "hockey stick" incision can be modified to 0 to $6 \mathrm{~cm}$. Liposuction is routinely done in the lateral chest wall fat and Tail of Spence, after the mastectomy and realignment of the superior and inferior horizontal chest incision lines, but before final cutting of the skin overlap. In patients with high BMI, with large folds of lateral chest wall breast, adipose, and skin, the incision can be lengthened beyond $7 \mathrm{~cm}$ up to approximately $8-9 \mathrm{~cm}$. An additional benefit of this unambiguous resection amount, is to achieve better symmetry given when two surgeons are simultaneously operating, one on each side.

\section{Natural chest ptosis}

Patients with higher BMI may seek an aesthetic outcome that favors a slight natural fold of the superior flap approximating the inferior border of the pectoralis muscle so as to accentuate the prominence of the muscle fold, and to be consistent with contour thickness of the upper and mid torso. Inadvertent thinning of the fatty tissue of the inferior end of the superior chest flap may result in a completely flat chest inconsistent with the remainder of the chest and upper abdomen.

This initial dissection plane is done by first dissecting the superior flap at the IMF down to the underlying pectoralis fascia. The incision line above the NAC is at a $45^{\circ}$ angle until approximately $5-7 \mathrm{~cm}$ below the clavicle.

\section{Nipple graft placement}

Compared to the nipple size, prominence, and position associated with feminine breasts, nipples on cis-male chests are typically smaller, have less projection, and are located more laterally and superiorly (16-19). Anatomic studies have demonstrated the diameter of cis-male nipples to be between 2.0 and $2.8 \mathrm{~cm}$. To account for this, the nipple grafts are harvested using a $25 \mathrm{~mm}$ cookie-cutter at the start of surgery. The grafts are later de-fatted with scissors at the back table. De-fatting the graft decreases projection while also increasing graft viability. The nipple position is determined lateral to the midline around the 4th-5th intercostal space, at a point approximately $2.5 \mathrm{~cm}$ above the incision and $2.5 \mathrm{~cm}$ lateral to the inferior horizontal IMF midline. This site of the nipple graft approximates the usual position of a male nipple when seated and in an upright position (16-19).

\section{Results}

Of the 73 patients in the total cohort, $39(53.4 \%)$ responded to the survey. Among the respondents, four declined to answer questions, while eight only partially completed the survey. In total, 27 (37.0\%) individuals provided complete data and were included in the final analysis. Patients were divided into four cohorts to complete the analysis: (I) periareolar incision, (II) inframammary fold incision, (III) preJuly 2019 hockey stick incision, (IV) post-July 2019 hockey stick incision. The post-July 2019 group is composed only of obese patients because of the limited sample size, as well as the technique being particularly effective in those with 
high BMI. The response rates for groups 1, 2, 3, and 4 were $46.2 \%, 60.0 \%, 25.0 \%$, and $66.7 \%$ respectively.

\section{Chart review}

There was no statistically significant difference determined among the four cohorts in terms of demographic variables of ethnicity, insurance type, co-morbidities, or substance use (Table 3). However, patients who underwent peri-areolar incision were significantly younger compared to the preJuly 2019 "hockey stick" group $(\mathrm{P}=0.003)$, and had lower BMI when compared with the other 3 cohorts $(\mathrm{P}<0.001)$. They were also associated with a significantly smaller volume of liposuction than the pre-July $(\mathrm{P}=0.001)$ and postJuly 2019 "hockey stick" groups $(\mathrm{P}=0.005)$, and a shorter duration of surgery, $(\mathrm{P}=0.018)$ (Table 4). In addition, patients who received the peri-areolar incision had a significantly smaller volume of tissue removed than patients in the preJuly 2019 ( $\mathrm{P}=0.026)$ and post-July 2019 "hockey stick" $(\mathrm{P}=0.001)$ groups (Figure 7).

In terms of post-operative details, there were no significant differences detected in the complications, postoperative ED visits, re-admissions, and re-operations amongst other cohorts. In addition, the time ranges for recovery time (i.e., physical activity with limitation versus that without) were comparable among the groups (Figure 8). Of note, there were differences in time duration between surgery to BODY-Q administration between groups, with the inframammary fold incision cohort having a longer time duration $(1,249.2 \pm 253.7$ days) compared to the other three cohorts $(\mathrm{P}<0.001)($ Table 5). Additionally, the difference in time from surgery to BODY-Q administration between the patients who underwent the "hockey stick" incision before (706.6 \pm 260.1 days) and after (194 \pm 112.1 days) July 2019 was also significant $(\mathrm{P}=0.006)$.

In terms of analysis by BMI, the wound dehiscence rate of the patients in the group of BMI $>30$ was significantly increased $(\mathrm{P}=0.008)$, compared to patients of $\mathrm{BMI}<25(0 \%$ versus $42.9 \%, \mathrm{P}<0.008$ ) (Table 6). Other post-operative outcomes, including number of post-operative ED visits, re-admissions, re-operations, and recovery time did not significantly differ among weight classifications.

\section{Patient satisfaction}

The BODY-Q survey was administered in order to assess patient satisfaction after chest masculinization surgery. By cohort, patients who underwent the "hockey stick" incision before July 2019 (Cohort 3) had significantly higher scores $(98.7 \pm 4.2)$ in the "Satisfaction with Doctor/Surgeon" module compared to the peri-areolar incision group $(85.83 \pm 13.45)(\mathrm{P}<0.001)$ (Table 7). All of the other modules, in addition to overall score, did not have significant differences amongst the cohorts.

Cohort 3 ("hockey stick" before July 2019) had the tendency of higher scores $(89.6 \pm 11.9)$ in the "Satisfaction with Chest" module compared to other groups, yet the difference did not achieve statistical significance $(\mathrm{P}=0.066)$. When classified by BMI, differences were seen within the "Appraisal of Body Contouring Scars" module $(\mathrm{P}=0.010)$, with patients of $\mathrm{BMI}<25$ demonstrating significantly higher scores $(87.70 \pm 12.31)$, thus higher satisfaction, compared to patients of $\mathrm{BMI}>30(69.00 \pm 17.62)(\mathrm{P}=0.007)$ (Table 8).

\section{Discussion}

This study details the technical approach of "hockey stick" incision, a refinement of existing DMFNG for transgender men and non-binary individuals. Previously published studies, most notably by Berry et al., Lo Russo et al. and Gonzalez et al., described alternative efforts to masculinize the chest wall by including a lateral extension of the inframammary fold incision into the axilla to emulate the lateral border of the pectoralis $(24,32,33)$. The technique described here modifies prior techniques through rotation of lateral chest wall tissue, anteriorly and superiorly into the axilla, cutting off excess tissue and minimizing the excess tissue at the tail of Spence and tightening the skin at the lateral chest wall. In performing these technical refinements, it has been suggested that such alignment of a cis-masculine appearing chest and masculine gender identity improves gender dysphoria for some patients.

This study is a preliminary study that investigates the differences between the hockey stick incision and other types of commonly-accepted incisions for chest wall masculinization in transgender men. In terms of differences between the incision types, we found that patients who underwent "hockey stick" and inframammary fold incisions had significantly greater tissue removed and less liposuction compared to patients who received the peri-areolar incision approach. This reflects the selection of surgical type, as patients who are offered peri-areolar incisions typically have a relatively lower BMI (24-26). When classified by BMI, it was found that patients of larger body habitus (BMI >30) had a significantly higher rate of wound dehiscence than normal weight patients. The longer incision required 
Table 3 Demographic variables of all patients undergoing chest masculinization surgery

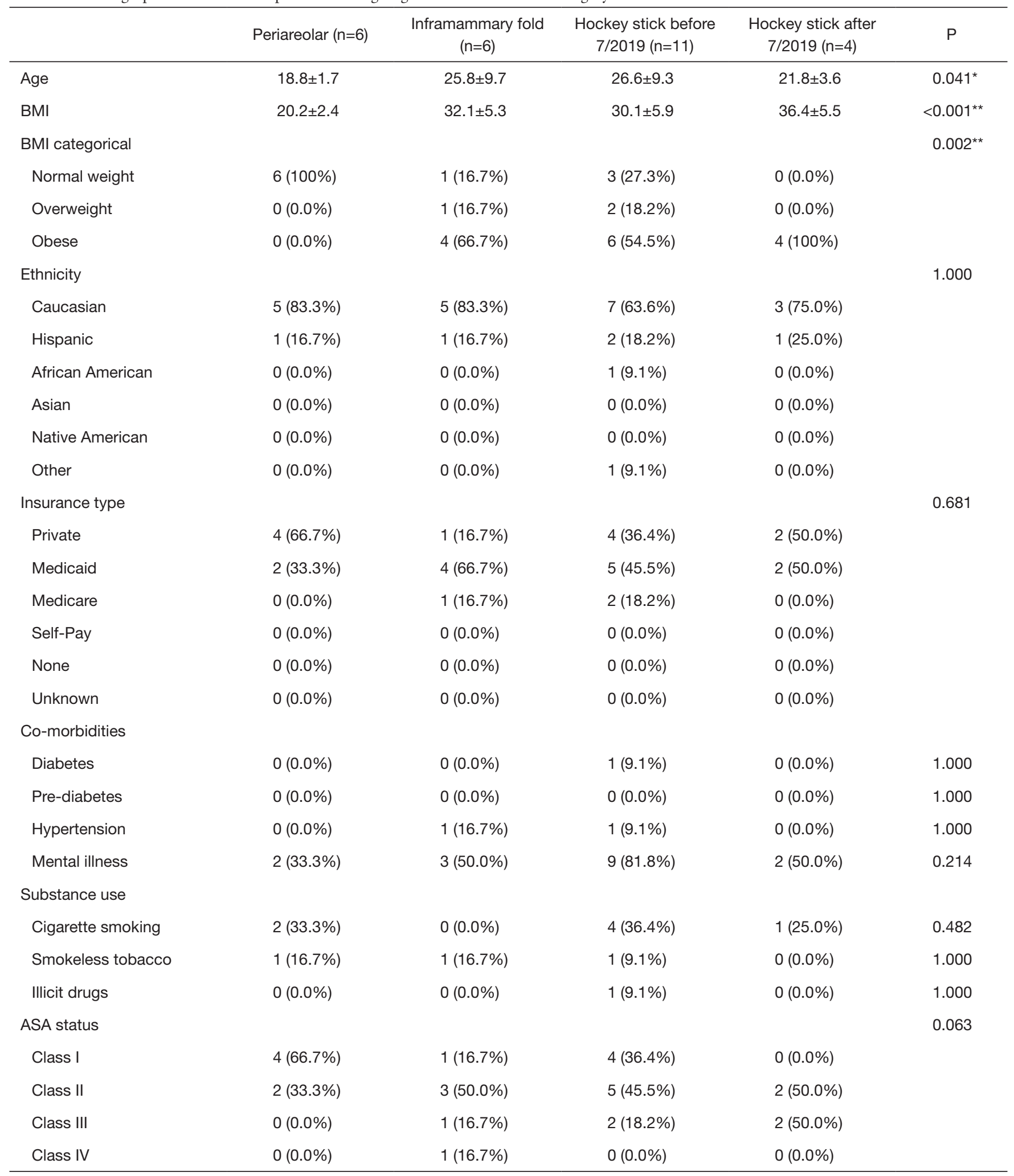

Statistical significance observed in post-hoc analysis; ${ }^{*} \mathrm{P}<0.05$; ${ }^{* *} \mathrm{P}<0.01$. Age, Cohort 1 vs. $3: \mathrm{P}=0.003$; $\mathrm{BMI}, \mathrm{Cohort} 1$ vs. 2 : $\mathrm{P}=0.003$, 1 vs. 3: $\mathrm{P}=0.006,1$ vs. $4: \mathrm{P}<0.001$; $\mathrm{BMl}$ categorical, Cohort 1 vs. $2: \mathrm{P}=0.006,1$ vs. $3: \mathrm{P}=0.009,1$ vs. $4 \mathrm{P}=0.005$. 
Table 4 Operative details across incision type

\begin{tabular}{|c|c|c|c|c|c|}
\hline & Periareolar $(n=6)$ & $\begin{array}{l}\text { Inframammary } \\
\text { Fold }(n=6)\end{array}$ & $\begin{array}{l}\text { Hockey stick before } \\
7 / 2019(n=11)\end{array}$ & $\begin{array}{c}\text { Hockey stick after } \\
7 / 2019(n=4)\end{array}$ & $P$ \\
\hline Volume of liposuction & $43.3 \pm 106.1$ & $350.0 \pm 427.8$ & $486.4 \pm 281.2$ & $650.0 \pm 267.7$ & $0.008^{\star \star}$ \\
\hline Volume of tissue removed (total) & $320.8 \pm 191.5$ & $1,769.5 \pm 946.8$ & $2,030.7 \pm 1,036.9$ & $3,623.7 \pm 1,312.9$ & $0.002^{*}$ \\
\hline Peri-operative morbidity & $0(0.0 \%)$ & $0(0.0 \%)$ & $0(0.0 \%)$ & $0(0.0 \%)$ & 1.000 \\
\hline
\end{tabular}

Statistical significance observed in post-hoc analysis; ${ }^{*} \mathrm{P}<0.05$; ${ }^{*} \mathrm{P}<0.01$. Liposuction, Cohort 1 vs. 3: $\mathrm{P}=0.001,1$ vs. 4 : $\mathrm{P}=0.005$; Volume of Tissue Removed, Cohort 1 vs. 3: $P=0.026,1$ vs. 4: $P=0.001$; Duration of Surgery, Cohort 1 vs. $2: P=0.018,1$ vs. $4: P=0.018$.

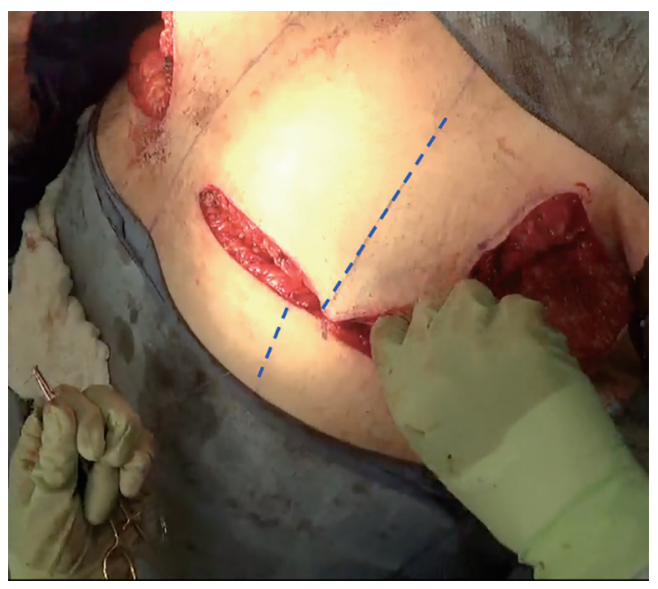

Figure 5 Shifting of the midline of the superior flap in the hockey stick incision. The blue dotted lines represent the midclavicular line marked at the beginning of surgery. In closing the incision, the point at the midclavicular line on the superior flap is reconnected to the inferior flap about $2 \mathrm{~cm}$ lateral to the midclavicular line. Because of the contour of the breast, the inferior incision is shorter in length than the superior incision, and this shift reduces the length discrepancy of excess that remains on the superior flap.

for patients with larger habitus might account for this difference. The need for additional tissue removal to correct lateral skin excess has longer incisions and extension into the axilla, risking dehiscence, as this area tends to be under additional tension while performing daily activities (i.e., abduction arm movements, particularly when wearing "pull over" garments) (24,32,33). Despite the discrepancy in volume of tissue removed and increased complication rate in higher BMI patients, this study found no differences in terms of patient satisfaction by incision type. Although our study is preliminary in nature and is limited by a small sample size, taken together, these findings suggest that the "hockey stick" approach confers comparable overall clinical outcomes relative to those associated with the peri-areolar incision. This is particularly notable since the peri-areolar incision is associated with fewer complications and are generally performed in healthier patients (24-26).

In terms of differences in patient satisfaction, BODY-Q results between patients who underwent the different incision types, the only statistically significant finding was that patients who underwent the "hockey stick" incision before 7/2019 had higher satisfaction with their surgeon than those who had surgery through a peri-areolar incision, even though all patients included in the analysis who underwent those two types of procedures, were performed by the same surgeon (JP). This finding could be related to increased time of surgery to survey administration. This variable is especially important to consider as an influential factor for healing time and its potential association with patient satisfaction from chest masculinization surgery. Another explanation for this finding may be the possibility of increased doctor-patient communication, which has been linked with improved patient-reported outcomes (39). The process of learning from the patient, eliciting their concerns, and implementing and refining the surgical technique may have resulted in increased communication between the senior author and patients during that time period (39).

In our analysis of BODY-Q results, other modules appeared to approach, yet not reach significance. In contrast to the findings of van de Grift et al., the "Satisfaction of Chest" and "Satisfaction of Nipples" modules did not yield significant differences between cohorts (38). Patients who underwent the "hockey stick" incision in our study, particularly before July 2019, reported scores in the "Satisfaction of Chest" module that approached statistical significance, and that could be limited by our smaller sample size $(\mathrm{P}=0.066)$. The patients in this cohort did have a significantly longer duration between the surgery 

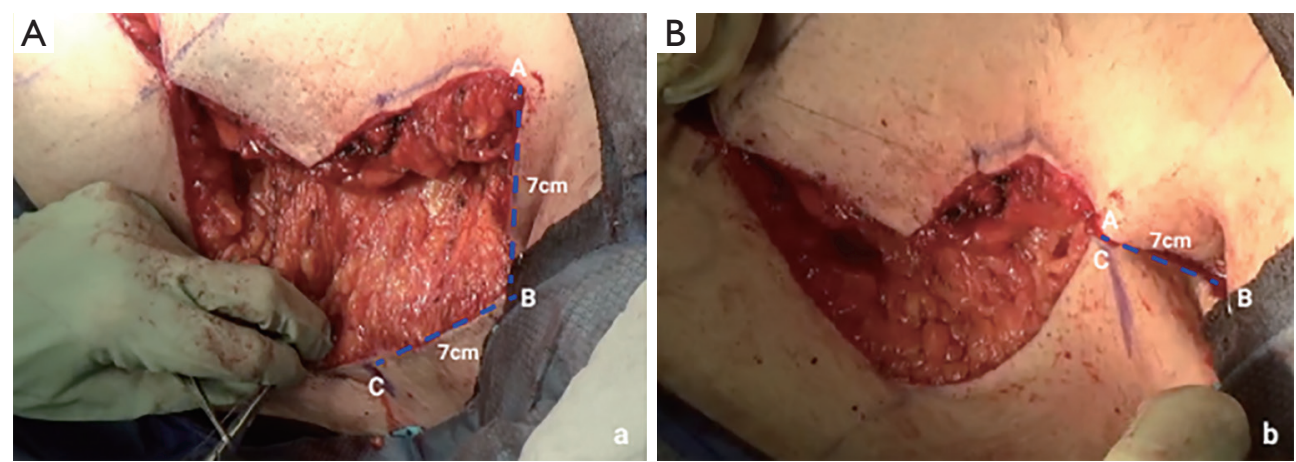

Figure 6 Re-approximating the axilla using the $7 \mathrm{~cm}$ markings. For orientation, the head is positioned toward the upper right of the images while the feet are at the bottom left. The images depict the axillary component of the "hockey stick" incision. (A) A represents the point at which the pectoralis meets the anterior axillary line. B represents the pivot point around which the inferior and superior flaps will be joined. C represents a point $7 \mathrm{~cm}$ from B. (B) Point $\mathrm{C}$ is brought to meet A. This pulls the lateral chest wall upward, which tightens the lateral chest wall.

Volume of Liposuction

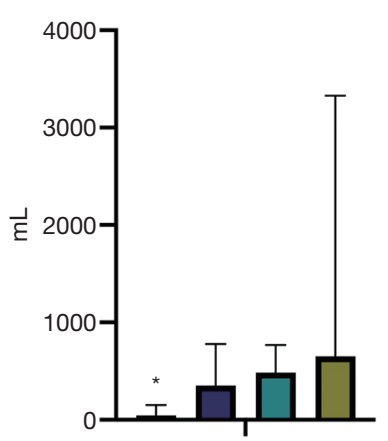

Volume of tissue removed $(\mathrm{L})$

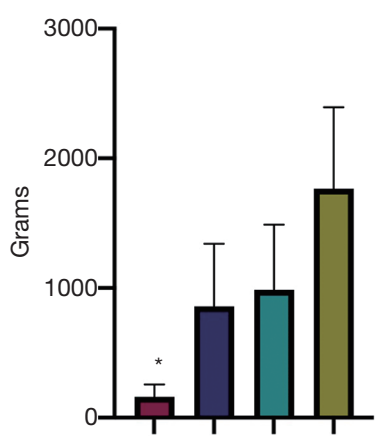

Operative time

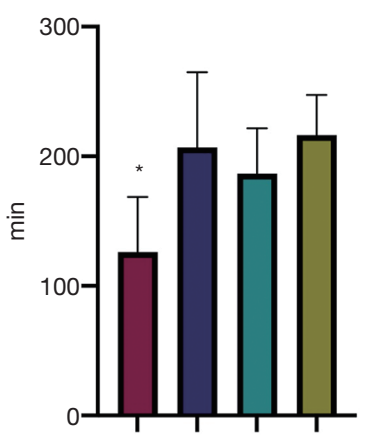

Volume of tissue removed $(\mathrm{R})$

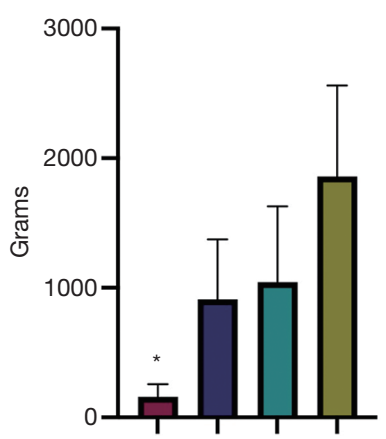

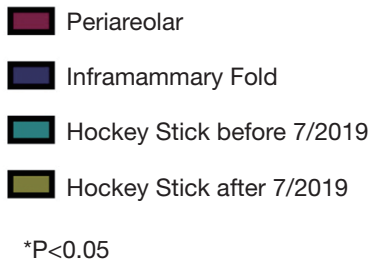

Volume of tissue removed (total)

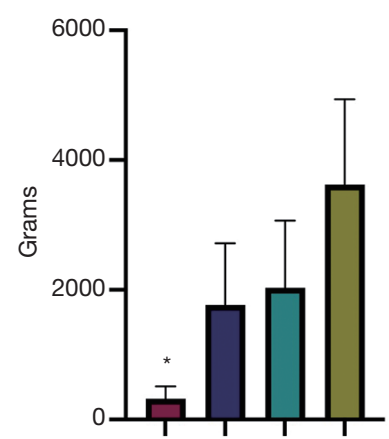

Figure 7 Comparison of operative details across incision types. The peri-areolar incision group is significantly different from the inframammary fold and hockey stick incision groups in terms of volume of liposuction, operative time, and amount of tissue removed. No other significant differences are found between the remaining groups.

and the administration of the BODY-Q survey. Thus, it is important to recognize the potential impact that time, and therefore, healing time from intervention, has on patient satisfaction (10). Future studies should explore the long- term satisfaction of the "hockey stick" incision through a larger sample size and uniform pre- and post-operative time-points for survey administration (30).

With respect to stratification by BMI, our study 
Table 5 Post-operative complications by incision type

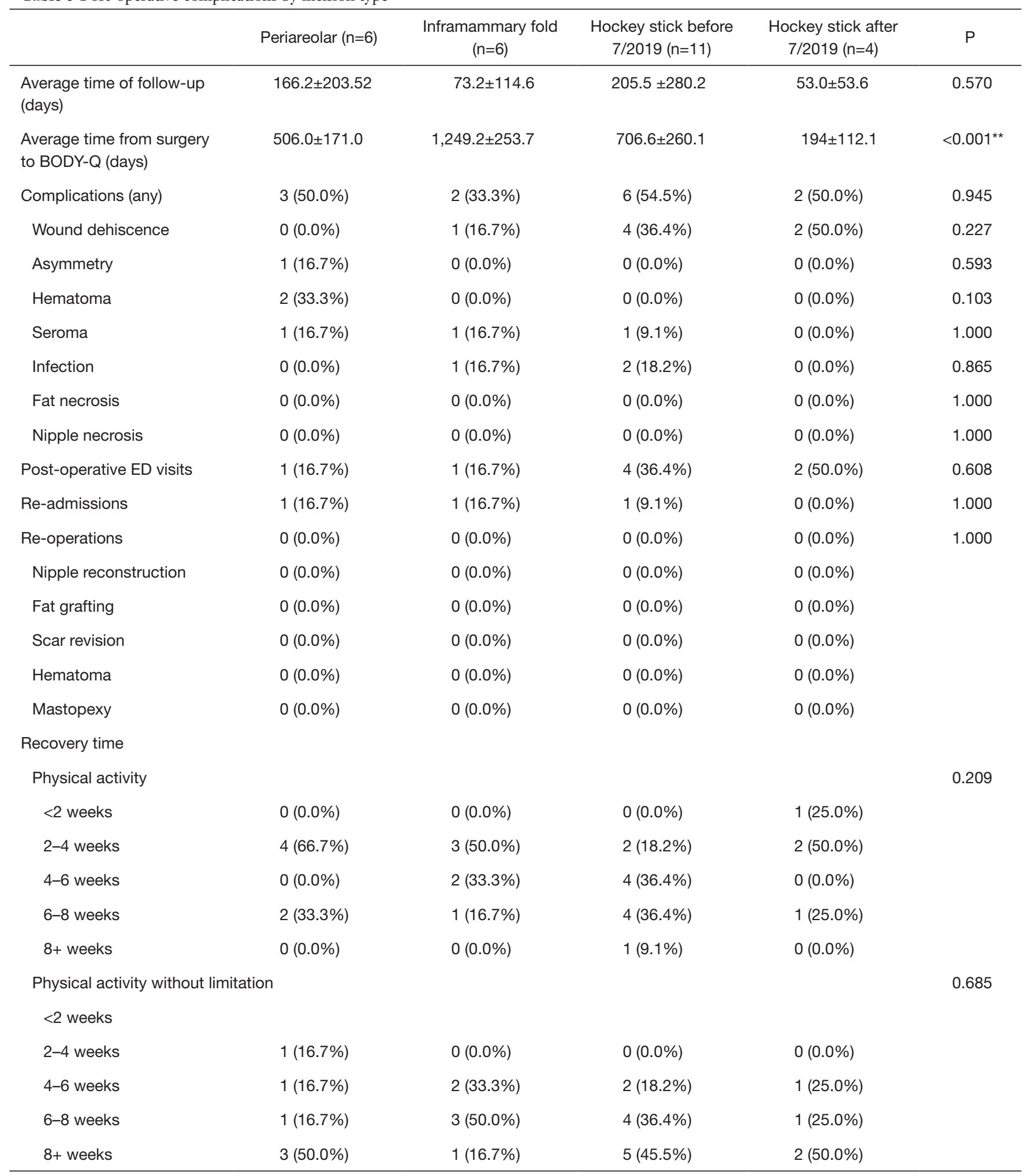

Statistical significance observed in post-hoc analysis; ${ }^{* *} \mathrm{P}<0.01$. Time from surgery to BODY-Q, Cohort 1 vs. $2: \mathrm{P}<0.001,2$ vs. $3: \mathrm{P}<0.001$, 2 vs. $4: \mathrm{P}<0.001,3$ vs. $4: \mathrm{P}=0.006$. 
Table 6 Post-operative complications by BMI

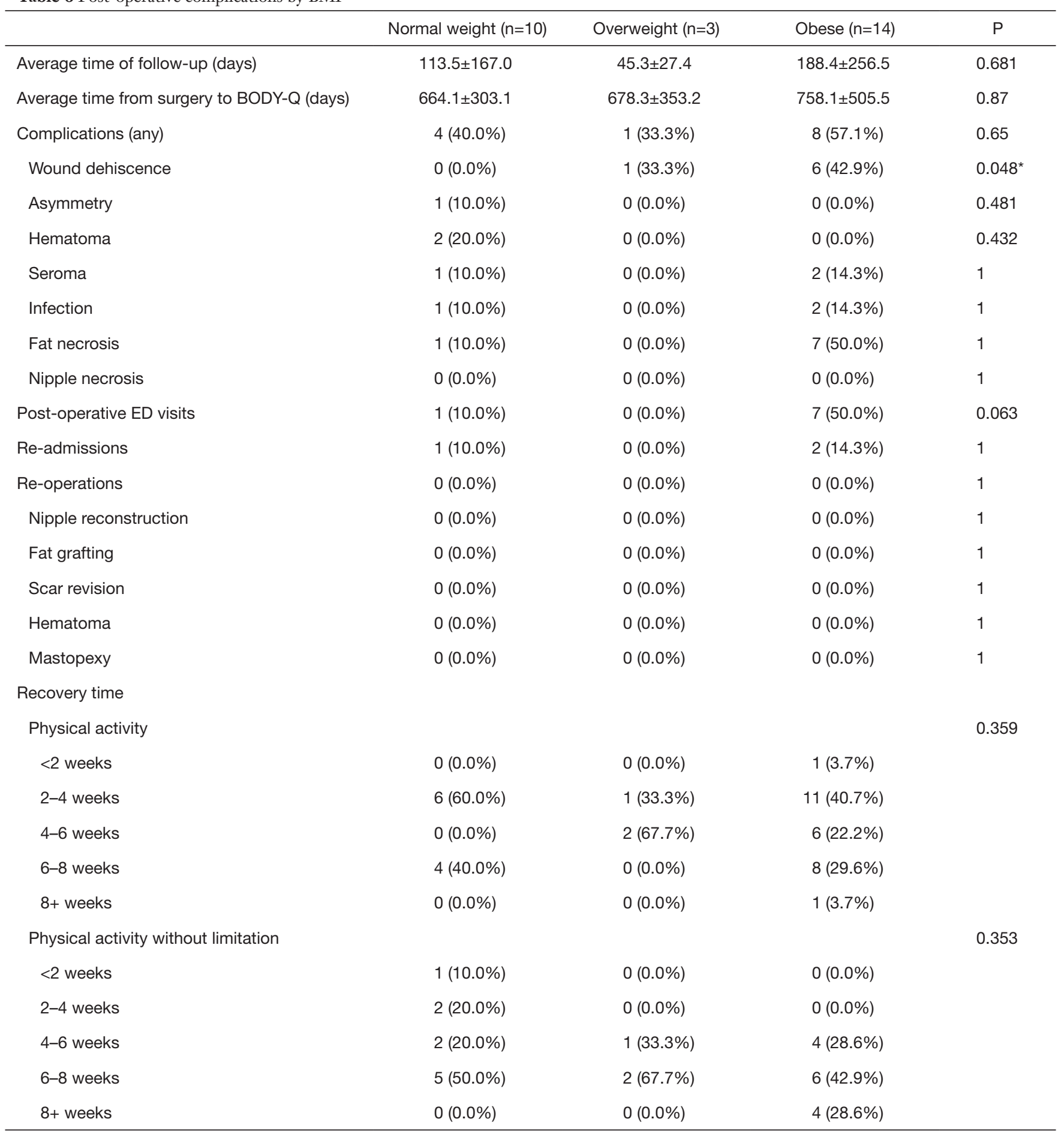

Statistical significance observed in post-hoc analysis; ${ }^{*} \mathrm{P}<0.05$. Wound dehiscence, normal weight vs. obese: $\mathrm{P}=0.008$.

revealed that patients with normal body weights had a significantly higher BODY-Q score, in the "Appraisal of Body Contouring of Scars" module, as compared to obese individuals (40). It is unclear, however, why body weight might impact level of scrutiny of scars. It is important to note that preferences and expectations related to scarring, 
Table 7 Body-Q modules by incision type

\begin{tabular}{|c|c|c|c|c|c|}
\hline & Periareolar $(n=6)$ & $\begin{array}{l}\text { Inframammary } \\
\quad \text { fold }(n=6)\end{array}$ & $\begin{array}{c}\text { Hockey stick before } \\
7 / 2019(n=11)\end{array}$ & $\begin{array}{l}\text { Hockey stick after } \\
7 / 2019(n=4)\end{array}$ & $P$ \\
\hline $\begin{array}{l}\text { Appearance-related psychosocial } \\
\text { distress }\end{array}$ & $32.50 \pm 25.68$ & $27.83 \pm 23.37$ & $25.73 \pm 8.6$ & $44.3 \pm 18.8$ & 0.704 \\
\hline Social function & $54.67 \pm 13.49$ & $65.67 \pm 14.39$ & $61.0 \pm 13.6$ & $60.5 \pm 7.3$ & 0.652 \\
\hline Psychological function & $58.17 \pm 17.60$ & $65.17 \pm 9.75$ & $67.6 \pm 14.6$ & $65.0 \pm 10.9$ & 0.847 \\
\hline Satisfaction with chest & $67.33 \pm 27.35$ & $62.83 \pm 34.45$ & $89.6 \pm 11.9$ & $72.0 \pm 24.7$ & 0.066 \\
\hline Satisfaction with nipples & $63.00 \pm 27.12$ & $68.33 \pm 39.33$ & $86.8 \pm 15.9$ & $74.3 \pm 25.3$ & 0.307 \\
\hline Appraisal of body contouring scars & $86.50 \pm 14.83$ & $62.50 \pm 32.20$ & $75.4 \pm 20.4$ & $68.5 \pm 16.9$ & 0.306 \\
\hline Overall score & $645.17 \pm 65.51$ & $657.67 \pm 178.55$ & $722.7 \pm 63.8$ & $669.3 \pm 33.7$ & 0.219 \\
\hline
\end{tabular}

Statistical significance observed in post-hoc analysis; ${ }^{*} \mathrm{P}<0.05$. Satisfaction with Doctor/Surgeon, Cohort 1 vs. Cohort 3: $\mathrm{P}<0.001$.

Table 8 Body-Q modules by patient BMI

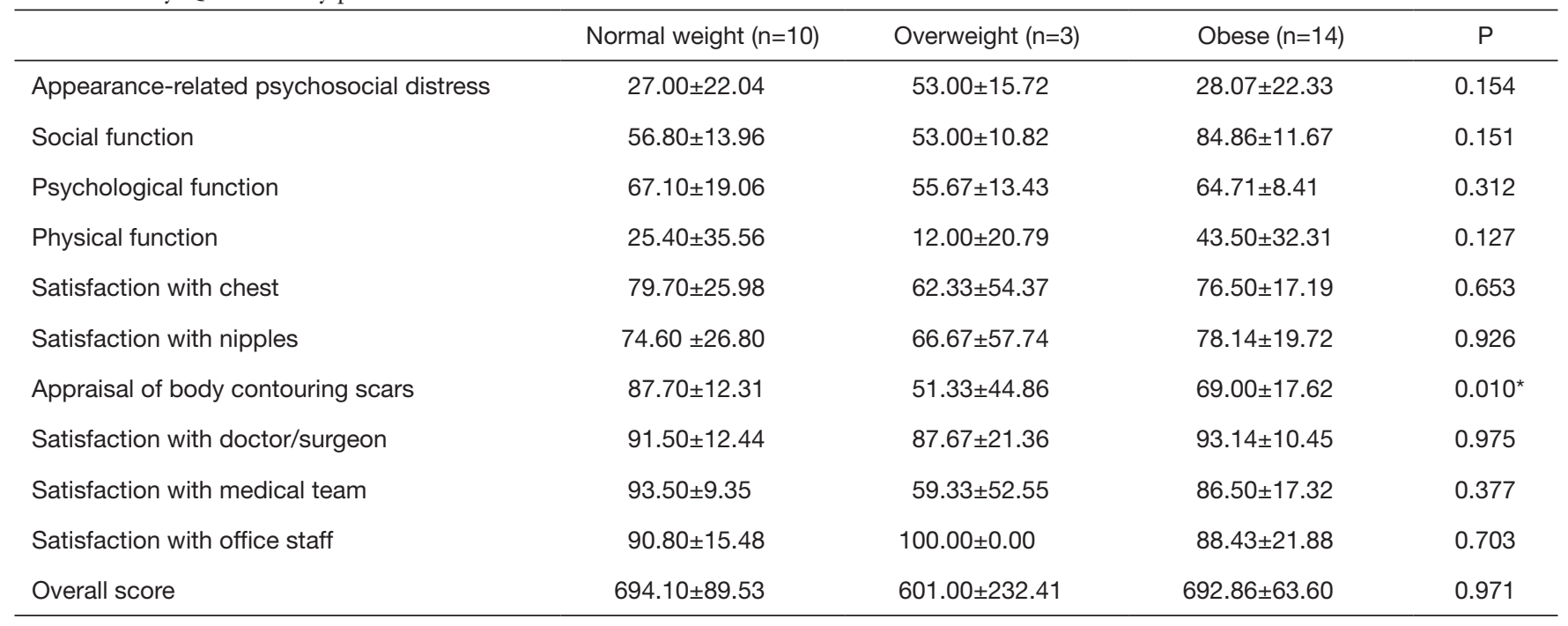

Statistical significance observed in post-hoc analysis; ${ }^{\star} \mathrm{P}<0.05$. Appraisal of body contouring scars, normal weight $v s$. obese: $\mathrm{P}=0.007$.

as well as decisions regarding whether or not to identify as transgender, vary greatly among patients and should be considered in pre-operative discussions. While for some, scarring is viewed as unattractive or potentially disfiguring, whereas others consider their surgical scars as positive marks of identity, resilience, or pride. For others who may not choose to publicly share their gender identities for personal reasons, scars are potentially endangering identifiers. These considerations were not accounted for in the BODY-Q module (34-38). This also underscores the fact that the appropriate reconstructive considerations are highly individualized, and that satisfaction is not necessarily a function of exclusively objective variables $(10,11,13)$.

To our knowledge, this study is the first to assess 


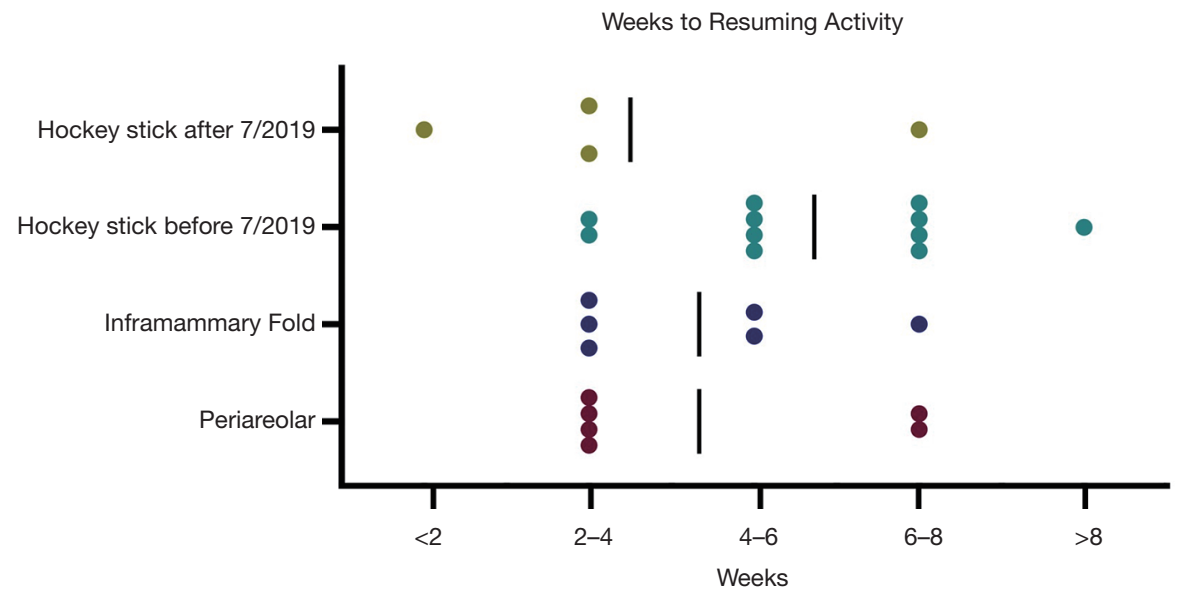

Figure 8 Weeks to any activity by individual patients undergoing various incision types. Each dot represents an individual patient, while the horizontal bars represent the mean recovery time of each group. The time to resuming activity is lowest for those who most recently underwent the hockey stick incision, although statistical significance was not observed.

BODY-Q scores by incision type, and serves as a starting point for future studies, with greater statistical power, to contribute to the evidence-base for chest masculinization surgery. There are several limitations to our study that warrant consideration. First, the small sample size of 27 patients restricts the ability to reach statistical significance within the majority of our analyses, although our response rate $(37 \%)$ is higher than the requirement for a general questionnaire (20\%) (41). This small sample size is prone to respondent bias, as those who responded to the survey may have done so because they had a higher satisfaction with their care. Our study serves as a starting point, and future studies investigating differences between incision types in this patient population are warranted. Second, all analyzed patients intentionally underwent a surgical reconstruction that achieved an aesthetic result that resembled a cis-masculine chest, which may not apply to patients who identify as trans-masculine or non-binary. These considerations are beyond the scope of the present study, but should be explored in future investigations. Third, our analysis and video communication does not include photographs of patients of varying racial and ethnic background, thus missing an opportunity to examine what effect skin color may be on the appraisal of scars (42). Despite these limitations, we believe that this study provides a useful technical approach towards chest masculinization surgery, and additionally, contributes helpful knowledge regarding patient satisfaction and clinical outcomes.

\section{Conclusions}

The "hockey stick" incision with free nipple grafts may alleviate gender dysphoria through reconstruction of a cismasculine appearing chest in transgender men. Our results suggest that this approach is a safe and effective technique for chest masculinization, particularly in those patients with moderate- to large and ptotic breast tissue, and for whom gender congruence is achieved with cis-masculine models. Additionally, the "hockey stick" approach confers patient satisfaction and clinical outcomes that are comparable with free nipple grafts and peri-areolar incision types. Our investigation serves as a starting point for future studies to further contribute to the evidence-base for chest masculinization.

\section{Acknowledgments}

Funding: None.

\section{Footnote}

Provenance and Peer Review: This article was commissioned by the editorial office, Annals of Translational Medicine for the series "Transgender Surgery". The article has undergone external peer review.

Reporting Checklist: The authors have completed the STROBE reporting checklist. Available at http://dx.doi. 


\section{Page 16 of 17}

org/10.21037/atm-20-7678

Data Sharing Statement: Available at http://dx.doi. org/10.21037/atm-20-7678

Conflicts of Interest: All authors have completed the ICMJE uniform disclosure form (available at http://dx.doi. org/10.21037/atm-20-7678). The series "Transgender Surgery" was commissioned by the editorial office without any funding or sponsorship. XNL and JAP served as the unpaid Guest Editor of the series. The authors have no other conflicts of interest to declare.

Ethical Statement: The authors are accountable for all aspects of the work in ensuring that questions related to the accuracy or integrity of any part of the work are appropriately investigated and resolved. The study was conducted in accordance with the Declaration of Helsinki (as revised in 2013). The study was approved by institutional review board of Yale School of Medicine (No.: 2000022992) and informed consent was taken from all individual participants.

Open Access Statement: This is an Open Access article distributed in accordance with the Creative Commons Attribution-NonCommercial-NoDerivs 4.0 International License (CC BY-NC-ND 4.0), which permits the noncommercial replication and distribution of the article with the strict proviso that no changes or edits are made and the original work is properly cited (including links to both the formal publication through the relevant DOI and the license). See: https://creativecommons.org/licenses/by-nc-nd/4.0/.

\section{References}

1. Cash T, Pruzinsky T. Body Images: Development, Deviance, And Change. New York: Guilford Press; 1990:51-79.

2. Sarwer D, Pruzinsky T, Cash T, et al. Psychological Aspects Of Reconstructive And Cosmetic Plastic Surgery. Philadelphia: Wolters Kluwer; 2006:37-47.

3. Bradford J, Reisner SL, Honnold JA, et al. Experiences of transgender related discrimination and implications for health: results from the Virginia Transgender Health Initiative Study. Am J Public Health 2013;103:1820-9.

4. Bauer GR, Hammond R, Travers R, et al. I don't think this is theoretical; this is our lives: how erasure impacts healthcare for transgender people. J Assoc Nurses AIDS
Junn et al. Hockey stick incision for chest masculinization surgery

Care 2009;20:348-61.

5. Roberts TK, Fantz CR. Barriers to quality health care for the transgender population. Clin Biochem 2014;47:983-7.

6. Safer JD, Coleman E, Feldman J, et al. Barriers to healthcare for transgender individuals. Curr Opin Endocrinol Diabetes Obes 2016;23:168-71.

7. Equality, N. C. f. T. (2015). US Transgender Survey. Available online: https://www.transequality.org/sites/ default/files/docs/USTS-Full-Report-FINAL.PDF

8. Health, W. P. A. f. T. (2019). Standards of Care for the Health of Transsexual, Transgender, and GenderNonconforming People. Available online: https://www. wpath.org/publications/soc

9. El-Hadi H, Stone J, Temple-Oberle C, et al. GenderAffirming Surgery for Transgender Individuals: Perceived Satisfaction and Barriers to Care. Plast Surg (Oakv) 2018;26:263-8.

10. Agarwal CA, Scheefer MF, Wright LN, et al. Quality of life improvement after chest wall masculinization in female-to-male transgender patients: A prospective study using the BREAST-Q and Body Uneasiness Test. J Plast Reconstr Aesthet Surg 2018;71:651-7.

11. Morselli PG, Summo V, Pinto V, et al. Chest Wall Masculinization in Female to Male Transsexuals: Our Treatment Algorithm and Life Satisfaction Questionnaire. Ann Plast Surg 2019;83:629-35.

12. Owen-Smith AA, Gerth J, Sineanth RC, et al. Association Between Gender Confirmation Treatments and Perceived Gender Congruence, Body Image Satisfaction, and Mental Health in a Cohort of Transgender Individuals. J Sex Med 2018;15:591-600.

13. Poudrier G, Nolan I, Cook T, et al. Assessing Quality of Life and Patient-Reported Satisfaction with Masculinizing Top Surgery: A Mixed-Methods Descriptive Survey Study. Plast Reconstr Surg 2019;143:272-9.

14. Wanta J, Gatherwright J, Knackstedt R, et al. "TRANS"questionnaire (TRANS-Q): a novel, validated pre- and postoperative satisfaction tool in 145 patients undergoing gender confirming mastectomies. Eur J Plast Surg 2019;42:527-30.

15. Ammari T, Sluiter EC, Gast K, et al. Female-to-Male Gender-Affirming Chest Reconstruction Surgery. Aesthet Surg J 2019;39:150-63.

16. Ramella V, Papa G, Arnez ZM, et al. Surgical therapy: chest wall contouring for female-to-male transsexuals. In: Trombetta C, Liguori G, Bertolotto M, eds. Management of Gender Dysphoria: A Multidisciplinary Approach. Milano, Italy: Springer; 2015: 281-287. 
17. Beer GM, Budi S, Seifert B, et al. Configuration and localization of the nipple-areola complex in men. Plast Reconstr Surg 2001;108:1947-52.

18. McGregor JC, Whallett EJ. Some personal suggestions on surgery in large or ptotic breasts for female to male transsexuals. J Plast Reconstr Aesthet Surg 2006;59:893-6.

19. Vigneswaran N, Lim J, Lee HJ, et al. A novel technique with aesthetic considerations in female-to-male transexuals nipple areolar complex reconstruction. J Plast Reconstr Aesthet Surg 2013;66:1805-7.

20. Wilson SC, Morrison SD, Anzai L, et al. Masculinizing Top Surgery: A Systematic Review of Techniques and Outcomes. Ann Plast Surg 2018;80:679-83.

21. Hage JJ, Bloem JJ. Chest wall contouring for female-tomale transsexuals: Amsterdam experience. Ann Plast Surg 1995;34:59-66.

22. Colić MM, Colić MM. Circumareolar mastectomy in female- to-male transsexuals and large gynecomastias: a personal approach. Aesthetic Plast Surg 2000;24:450-4.

23. Namba Y, Watanabe T, Kimata Y. Mastectomy in femaleto-male transsexuals. Acta Med Okayama 2009;63:243-7.

24. Berry MG, Curtis R, Davies D. Female-to-male transgender chest reconstruction: a large consecutive, singlesurgeon experience. J Plast Reconstr Aesthet Surg 2012;65:711-9.

25. Frederick MJ, Berhanu AE, Bartlett R. Chest surgery in female to male transgender individuals. Ann Plast Surg 2017;78:249-53

26. Bluebond-Langner R, Berli JU, Sabino J, et al. Top surgery in transgender men: how far can you push the envelope? Plast Reconstr Surg 2017;139:873e-882e.

27. Donato DP, Walzer NK, Rivera A, et al. Female-to-male chest reconstruction: a review of technique and outcomes. Ann Plast Surg 2017;79:259-63.

28. McEvenue G, Xu FZ, Cai R, et al. Female-to-male gender affirming top surgery: A single surgeon's 15-year retrospective review and treatment algorithm. Aesthet Surg J 2017;38:49-57.

29. van de Grift TC, Elfering L, Bouman MB, et al. Surgical indications and outcomes of mastectomy in transmen: a prospective study of technical and self-reported measures. Plast Reconst Surg 2017;140:415e-424e.

30. Morselli PG, Summo V, Pinto V, et al. Chest Wall Masculinization in Female-to-Male Transsexuals: Our Treatment Algorithm and Life Satisfaction Questionnaire. Ann Plast Surg 2019;83:629-35.

31. Cohen WA, Shah NR, Iwanicki M, et al. Female-to-Male
Transgender Chest Contouring: A Systematic Review of Outcomes and Knowledge Gaps. Ann Plast Surg 2019;83:589-93.

32. Lo Russo G, Tanini S, Innocenti M. Masculine Chest-Wall Contouring in FtM Transgender: a Personal Approach. Aesthetic Plast Surg 2017;41:369-374.

33. Gonzalez E, Frey JD, Bluebond-Langner R. Technical Refinements in Gender-Affirming Top Surgery. Plast Reconstr Surg 2020;146:38-40.

34. BODY-Q: Measuring What Matters to Patients. Available online: http://qportfolio.org/body-q/.

35. Geerards D, Klassen A, Hoogbergen M, et al. Streamlining the Assessment of Patient-Reported Outcomes in Weight Loss and Body Contouring Patients: Applying Computerized Adaptive Testing to the BODY-Q. Plast Reconstr Surg 2019;143:946e-955e.

36. Klassen AF, Kaur M, Poulsen L, et al. Development of the BODY-Q Chest Module Evaluating Outcomes following Chest Contouring Surgery. Plast Reconstr Surg 2018;142:1600-8.

37. Poulsen L, Klassen A, Rose M, et al. Patient-Reported Outcomes in Weight Loss and Body Contouring Surgery: A Cross-Sectional Analysis Using the BODY-Q. Plast Reconstr Surg 2017;140:491-500.

38. van de Grift TC, Elfering L, Greijdanus M, et al. Subcutaneous mastectomy improves satisfaction with body and psychosocial function in Trans men: findings of a cross-sectional study using the BODY-Q chest module. Plast Reconstr Surg 2018;142:1125-32.

39. Belasen, A, Belasan AT. Doctor-patient communication: a review and rationale for using an assessment framework. J Health Organ Manag 2018;32:891-907.

40. CDC (2020). Adult Body Mass Index (BMI)." Retrieved October 4, 2020. Available online: https://www.cdc.gov/ obesity/adult/defining.html.

41. "Instructions for Authors." Plast Reconstr Surg. Available online: http://edmgr.ovid.com/prs/accounts/ifauth.htm

42. Visscher MO, Bailey JK, Hom DB. Scar treatment variations by skin type. Facial Plast Surg Clin North Am 2014;22:453-62.

Cite this article as: Junn A, Khetpal S, Smetona J, Dinis J, Hirschman A, Mozaffari MA, Singh A, Ching AH, Alperovich M, Lu X, Persing JA. Hockey stick incision: a modified technique for chest wall masculinization. Ann Transl Med 2021;9(7):600. doi: 10.21037/atm-20-7678 